\title{
Relevance of Family in Academic Success on Children
}

\section{Patricia Martínez Lanz, Ana Cristina Losada Fernández, Fabiola Pecchioni Fernández, Martha Patricia Hernández Valdez}

Universidad Anáhuac México, México City, México

Email:pmlanz@anahuac.mx

How to cite this paper: Lanz, P.M., Fernández, A.C.L., Fernández, F.P. and Valdez, M.P.H. (2017) Relevance of Family in Academic Success on Children. Health, 9, 279-288.

https://doi.org/10.4236/health.2017.92019

Received: November 8, 2016

Accepted: February 14, 2017

Published: February 17, 2017

Copyright (c) 2017 by authors and Scientific Research Publishing Inc. This work is licensed under the Creative Commons Attribution International License (CC BY 4.0).

http://creativecommons.org/licenses/by/4.0/ (c) (i) Open Access

\begin{abstract}
The purpose of this study was to analyze the relationship between academic success and functional and dysfunctional families. A non-experimental, crosssectional, descriptive correlational design was used. A convenience sample of 200 children between 6 and 13 years old, primary and junior high school students was conducted (32.3\% were female and $67.7 \%$ were male). To assess the relationship, a study case of 21 reagents was designed to empty the obtained information from medical review records from a psychopedagogic clinic. Academic success was measured as from the revision of informal tests and standardized tests. Results showed that the population levels of academic success were average. However, a significant relationship between the age of the parents and the level of academic success was found, indicating that these variables are associated with this problem. Besides that, it was found that there is a tendency in children with cognitive, emotional and sensory problems reflected in low academic success. The findings provide information that could be considered for the development of programs of psychopedagogic intervention to treat children with learning disabilities and low academic success.
\end{abstract}

\section{Keywords}

Academic Success, Low Academic Success, Functional Family, Dysfunctional Family, Children

\section{Introduction}

The child is a human being growing, who needs a mental structure that allows the development of self-trust and confidence in the future. He must have adequate self-esteem with present parents guiding and containing his needs. In this regard, Lauro Estrada Ph.D. [1] mentions in his book named Life Cycle that biological and psychological structure of a human family must go through six 
stages (for a proper growth and development), no matter how painful can be this process be for the respective members: 1) detachment; 2) meeting; 3) children; 4) adolescence; 5) reunion; 6) old age.

The family concept emitted in 20 century is different from the one used today. Nowadays, families go through the phases described by Estrada [1], but at different times and sequences of life. For example, children spend detachment stage before the estimated time and not for dating, but they leave their home to expand academic studies and at the same time, to find a better job. After meeting these goals it's when they start dating. In the past, mothers spent most of the time with their children, taking them to school, helping with homework, aware of diseases and welfare in general. But now, children have other priorities like their parents; this is why children no longer live with them and are cared for by others. This situation, even if it is hard to believe, has a negative effect because it breaks with the stability and family structure, generating problems in children in their academic, personal, social and work life.

According to Estrada [1], the family regulates its own operation through two mechanisms in order to keep harmony:

- The homeostatic control. It is the balance that exists in the group. It is understood as "a system that gives structure of time and space to the family, i.e. each of the members is placed in a particular position, and when this one is abandoned, all members react retaining their positions in order to preserve the structure of the system" [1].

- The communication network. It is about the code messages that the family creates to communicate and this must be respected by all the members.

If the family holds the two mechanisms, the members set specific roles inside the group. This helps the group balance, establishing relationships within the family. That's why when a member takes the incorrect role, the whole system loses balance, affecting the three areas of a child's development: academic, social and emotional.

Unfortunately not all families have achieved the stability with current changes; at most of the time the roles are mixed. By going through divorce or separation, there is the doubt about who should take care of the children, and sometimes parents focus so much on occupational development or physical appearance, that they detached from all house responsibility.

According to Beltran and Bueno [2] in order to study the academic performance and the relationships with family, the connection between several variables such as: emotional climate, skills, cognitive aspects, psycholinguistic aspects, culture, attitudes, values, economy, among others has been investigated. For a good school performance as well as an optimal relationship between parents and children there must be: united homes, appropriate family life and good mental and physiological health; this refers to a functional family: a social group consisting of parents and children living in interdependence [3]. It means that all members need each other and also have an emotional link, which lead everyone to have a good relationship. 
Low academic performance is the result of learning from the educative activity of the teacher and produced by the students. However, not all-learning activity is exclusively the result of the teacher's actions (Tourón, cited in [4]), because knowledge involves several factors including personal factors (intelligence, skills, personality, anxiety, motivation, self-concept); social factors (characteristics of the environment in which the student lives); and family factors (family socioeconomic status, structure, climate, etc.) [5].

"Parent's education, home stability, economic issues, cultural interests, home relationships, and cultural community opportunities are factors that determine the quantity and quality of the information received by the child, producing learning" [6].

Frequently, a low performance situation involves a number of problems such as emotional stress affecting personal development, studies and may even cause poor social integration. Speaking about low academic performance, it will not be talking about clumsy students because in fact they are intelligent, but they cannot perform as expected and, therefore, they tend to be labeled as bad students [7]; hence, the aim of this study is to analyze the relation between functional and dysfunctional families in the academic performance.

\section{Methodology}

This investigation is correlational, descriptive and quantitative (case study), the research design is non-experimental and transversal. Collection of information was based on the review of 200 records from a psychopedagogical clinic, which were randomly selected.

\subsection{Process}

A format was designed to empty the information obtained, it consisted of 21 reagents that concern development history, school performance, reason of consultation, medical, parental and hereditary data. The technique used was structured: list of reactants on the subject that was given (Table 1), with not free field and the specific problem was focused on school failure.

\subsection{Population}

- Middle class

- Medium-low class

\subsection{Sample}

- Patients attending a psychopedagogical clinic, both genders between 6 and 13 years of age.

\section{Results}

Table 2 shows sociodemographic characteristics of studied population. The analysis was made considering these characteristics such as sex, age, education, study group and type of school. In terms of gender, $67.7 \%$ were male and $32.3 \%$ 
Table 1. List of reactants.

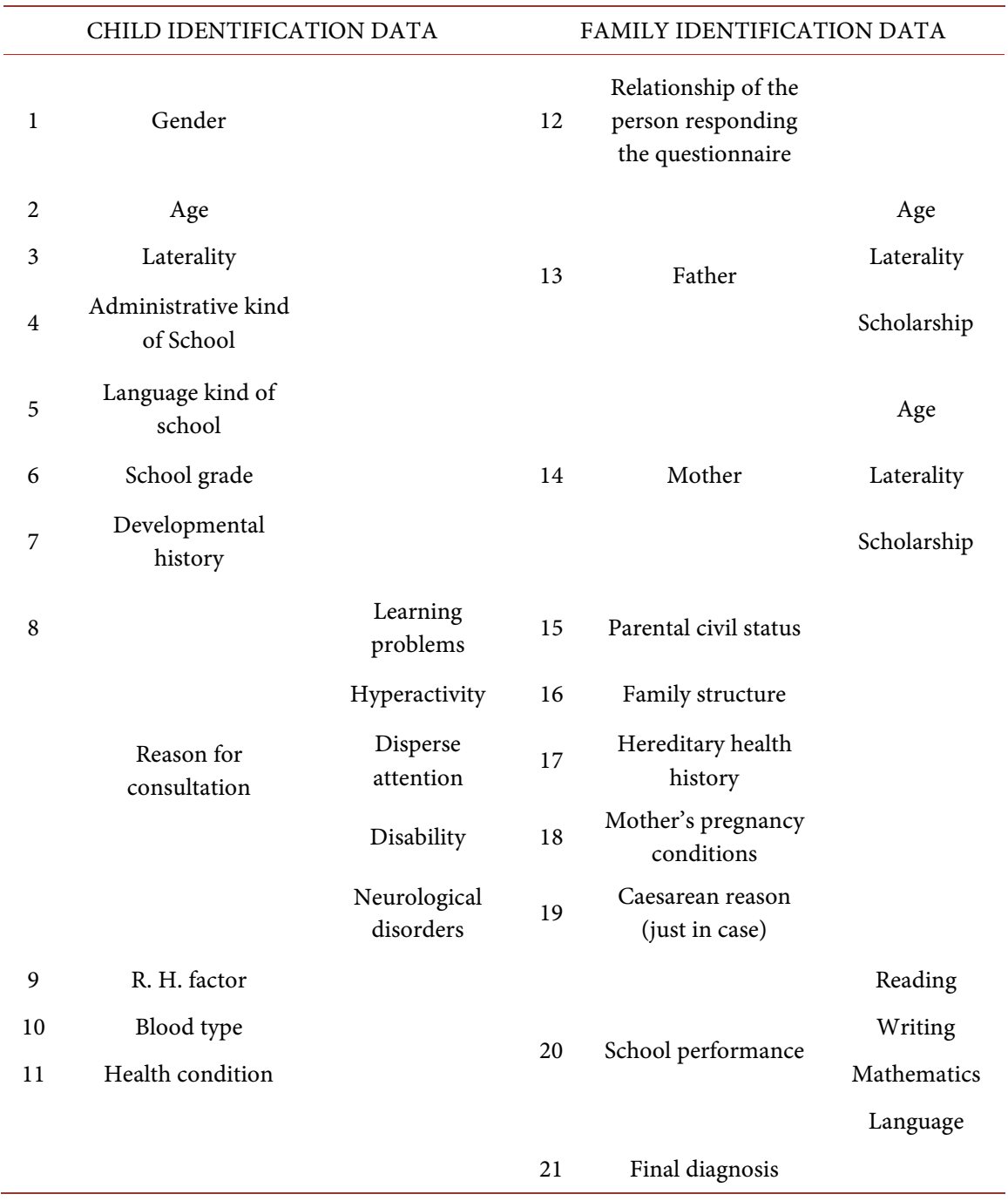

Table 2. Characteristics of children.

\begin{tabular}{ccc}
\hline & CHARACTERISTICS OF CHILDREN & \\
\hline Variable & Characteristic & Percentage \\
\hline Sex & Female & $32.3 \%$ \\
Age & Male & $67.7 \%$ \\
\hline & 4 to 10 years & $62 \%$ \\
\hline Scholar level & 11 to 16 years & $38 \%$ \\
\hline & Kindergarten & $36.2 \%$ \\
& Low elementary education & $26.1 \%$ \\
\hline Sype of school & High elementary education & $25.1 \%$ \\
& Junior high school & $12.6 \%$ \\
\hline
\end{tabular}


female. The group was: $62.0 \%$ between 4 to 10 years old and $38 \%$ between 11 and 16. the school level with the highest percentage is low elementary school (26.1\%) and finally, there are more children from public schools (57.1\%) than private schools (42.9\%).

About language development, seen in Table 3 that $70.2 \%$ had appropriate development of expression and understanding. About motor development, 69.2\% had adequate crawling and $30.8 \%$ did not crawl, and $100 \%$ of the children had an adequate march.

The results indicated laterality of the child as: $88.3 \%$ right and $11.7 \%$ lefthanders and related to final development, $90.9 \%$ of children had an adequate one.

About parental characteristics, it was observed that $48.2 \%$ of the parents are between 31 - 40 years; mothers belong to this group (Table 4). Also non-significant differences were observed in parent's age. In the other hand, there are differences between mothers and fathers scholarship: $49.7 \%$ of the fathers have junior high school or high school, and $45.0 \%$ of mothers have professional studies or are postgraduate. About marital status, non-significant differences were observed, being cohabiting and married the status with the highest percentage (75.9\%), then separated and divorced (20.1\%) and finally single (4.0\%).

The analysis considering the diagnosis of children such as cognitive problems, emotional difficulties, ADD/ADHD, learning/sensory/physical disorders reported the following data (Table 5).

Through final diagnosis, it was found that: $32 \%$ of children have physical sensory problems, $26.7 \%$ have cognitive problems, $21.3 \%$ have emotional problems, $12 \%$ have ADD/ADHD and $4 \%$ have learning disabilities and other disorders.

Based on the results obtained from Chi Square analysis on high school performance, we can see that $11.9 \%$ of children attending to monolingual and $20.5 \%$ of children who attend to bilingual school have this kind of development (Figure 1).

Table 3. Development characteristics.

\begin{tabular}{ccc}
\hline \multicolumn{3}{c}{ DEVELOPMENT CHARACTERISTICS } \\
\hline Language development & Adequate & Inadequate \\
\hline Comprehension & $28.3 \%$ & - \\
Expression & $1.5 \%$ & - \\
Both characteristics & $70.2 \%$ & - \\
\hline Motor development & Adequate & Inadequate \\
\hline Neck & $100 \%$ & - \\
Sedestation & $100 \%$ & - \\
Bipedestation & $77.1 \%$ & $22.9 \%$ \\
Crawl & $69.2 \%$ & $30.8 \%$ \\
Walk & $100 \%$ & - \\
Final development & $90.9 \%$ & $9.1 \%$ \\
\hline
\end{tabular}


Table 4. Parental characteristics.

\begin{tabular}{ccccc}
\hline \multirow{4}{*}{ Father } & Percentage & Mother & Percentage \\
\cline { 2 - 5 } Age & $24-30$ years & $5.7 \%$ & $24-30$ years & $14.6 \%$ \\
& $31-40$ years & $48.2 \%$ & $31-40$ years & $50.5 \%$ \\
& $41-50$ years & $34.2 \%$ & $41-50$ years & $29.8 \%$ \\
& $51-67$ years & $11.9 \%$ & $51-64$ years & $5.1 \%$ \\
\hline \multirow{4}{*}{ Scholarship } & Uneducated-elementary & $8.6 \%$ & Uneducated-elementary & $13.1 \%$ \\
& education & & education & \\
& Junior high & $49.7 \%$ & Junior high & $41.9 \%$ \\
& school-high school & & school-high school & \\
& Professional-postgraduate & $41.7 \%$ & Professional-postgraduate & $45.0 \%$ \\
\hline \multirow{3}{*}{ Marital status } & Cohabiting and married & $75.9 \%$ & Cohabiting and married & $75.9 \%$ \\
& Separated and divorced & $20.1 \%$ & Separated and divorced & $20.1 \%$ \\
& Single & $4.0 \%$ & Single & $4.0 \%$ \\
\hline
\end{tabular}

Table 5. Final diagnosis.

FINAL DIAGNOSIS

$\begin{array}{cc}\text { Cognitive } & 26.7 \% \\ \text { Emotional } & 21.3 \% \\ \text { ADD/ADHD } & 12 \% \\ \text { Learning } & 4 \% \\ \text { Sensorial/Physical disorders } & 32 \% \\ \text { Other disorders } & 4 \%\end{array}$

${ }^{*} \mathrm{ADD} / \mathrm{ADHD}$ : persistent pattern of inattention and/or hyperactivity-impulsivity that interferes with functioning or development, has symptoms presenting in two or more settings (e.g. at home, school, or work; with friends or relatives; in other activities), and negatively impacts directly on social, academic or occupational functioning. Several symptoms must have been present before the age of 12 [8].

\section{ACADEMIC PERFORMANCE ACCORDING TO SCHOOL TYPE}

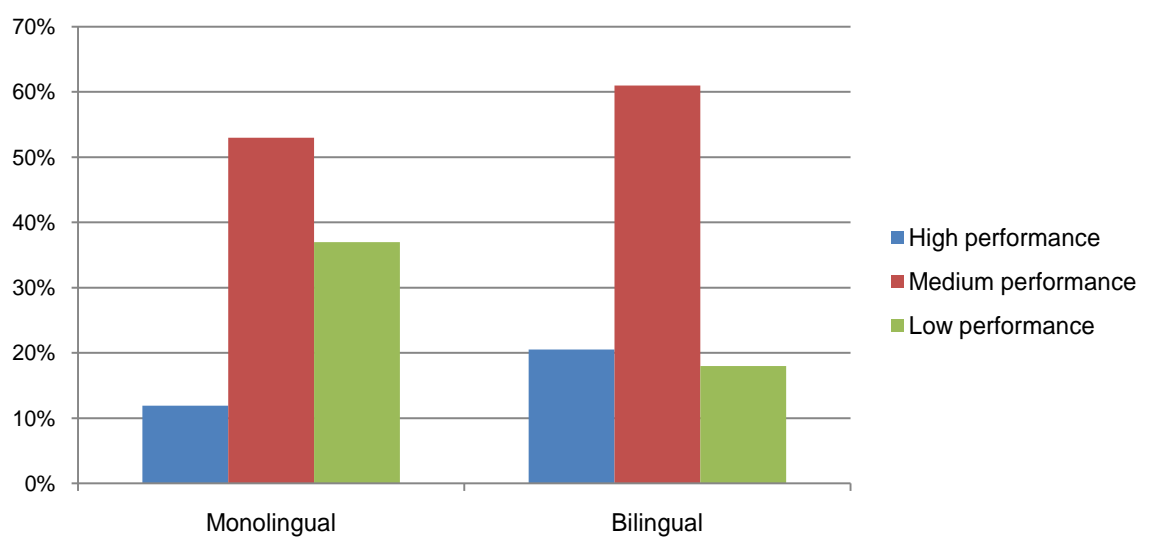

Figure 1. Academic performance according to school type. 
The analysis between academic performance and group of children's age (Figure 2), indicate that kids between 4 and 10 years old (12\%) have a high scholar performance, while kids between 11 and 16 years old (10.5\%) show a lower level of scholar performance.

According to parental age, fathers between 51 to 67 years old have children with higher academic performance (34.8\%) and mothers between 41 to 50 years old have children with higher academic performance (28.3\%) than parents of 40 years or less (Figure 3 and Figure 4).

Analysis on children's scholar grade, and high academic performance, indicate that $14.5 \%$ of children in Kindergarten show this level; in low elementary school the $8.2 \%$ have it, in high elementary school $25.5 \%$ have a high performance and $12.5 \%$ on Junior high school, as shown in Figure 5.

About parental marital status and children academic performance, the results indicate that there are non-significant differences between both aspects, which means that there isn't great variability between the academic performance of

\section{ACADEMIC PERFORMANCE ACCORDING TO AGE}

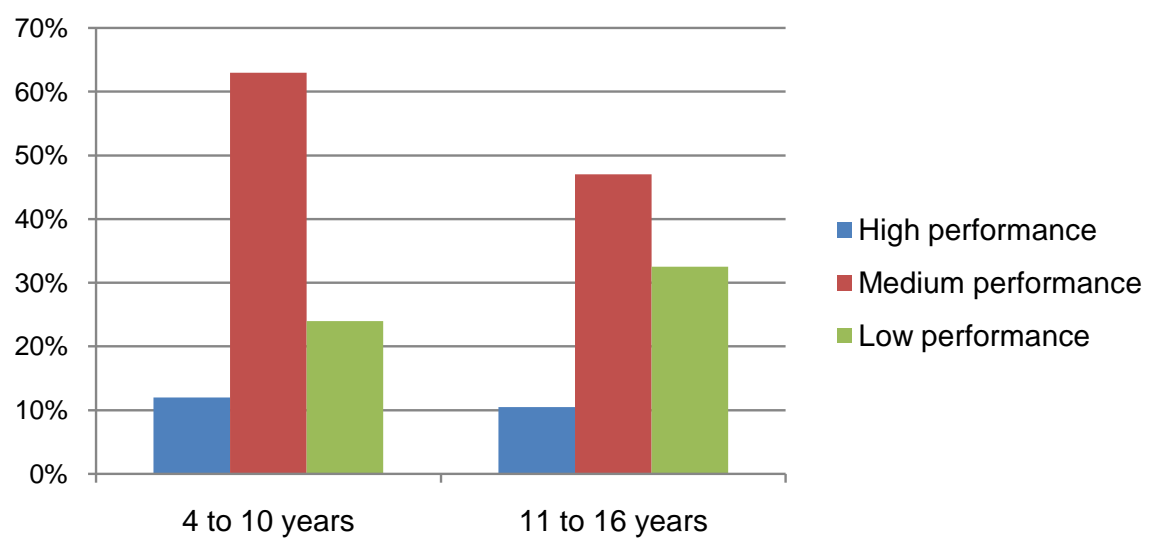

Figure 2. Academic performance according to age.

\section{ACADEMIC PERFORMANCE ACCORDING TO FATHER'S AGE}

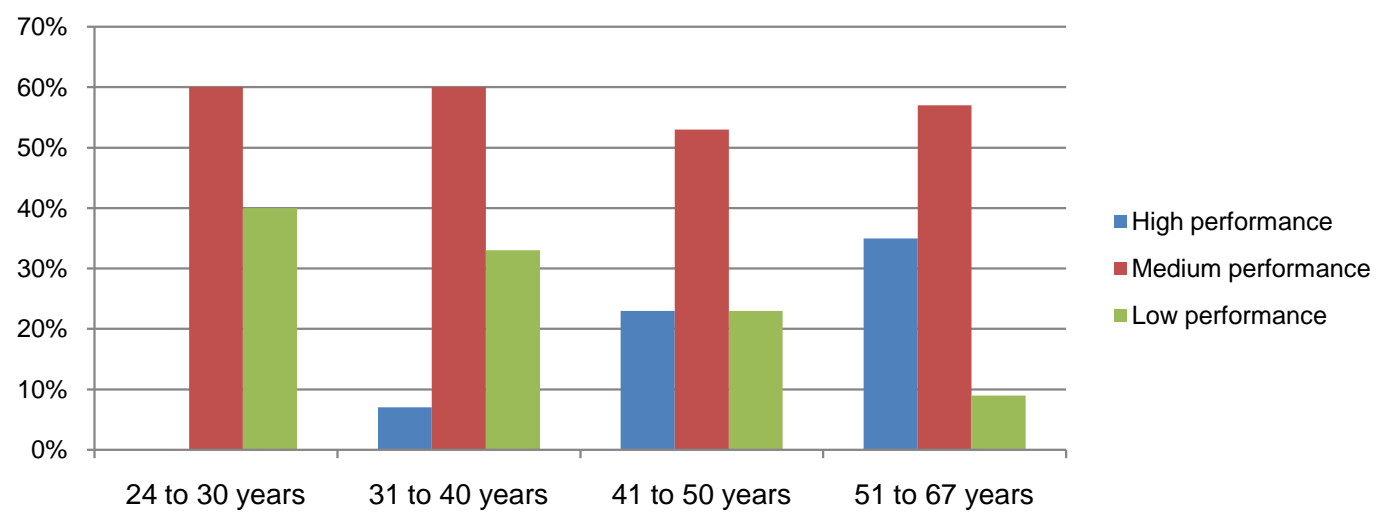

Figure 3. Academic performance according to father's age. 
ACADEMIC PERFORMANCE ACCORDING TO MOTHER'S AGE

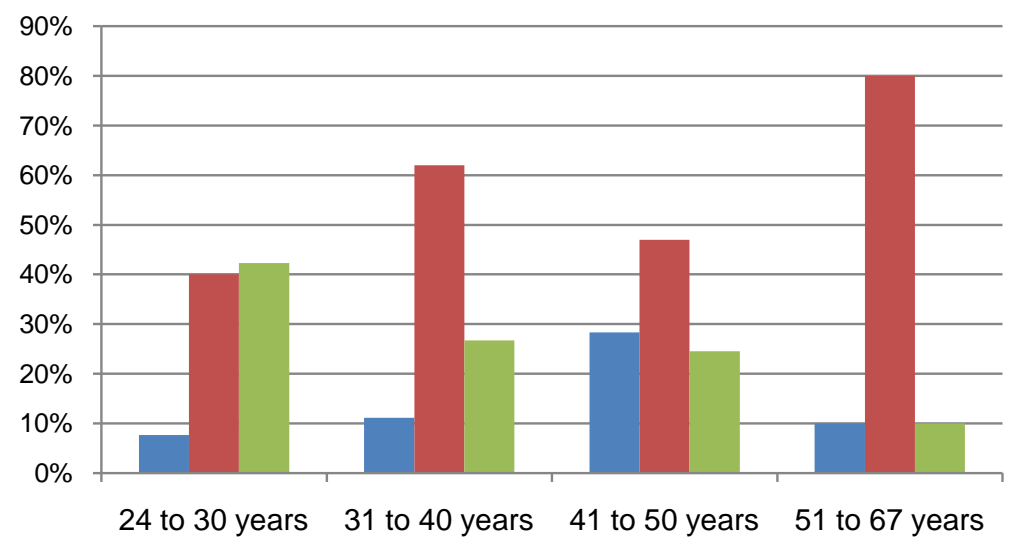

- High performance

- Medium performance

- Low performance

Figure 4. Academic performance according to mother's age.

\section{ACADEMIC PERFORMANCE ACCORDING TO CHILDREN'S SCHOLAR GRADE}

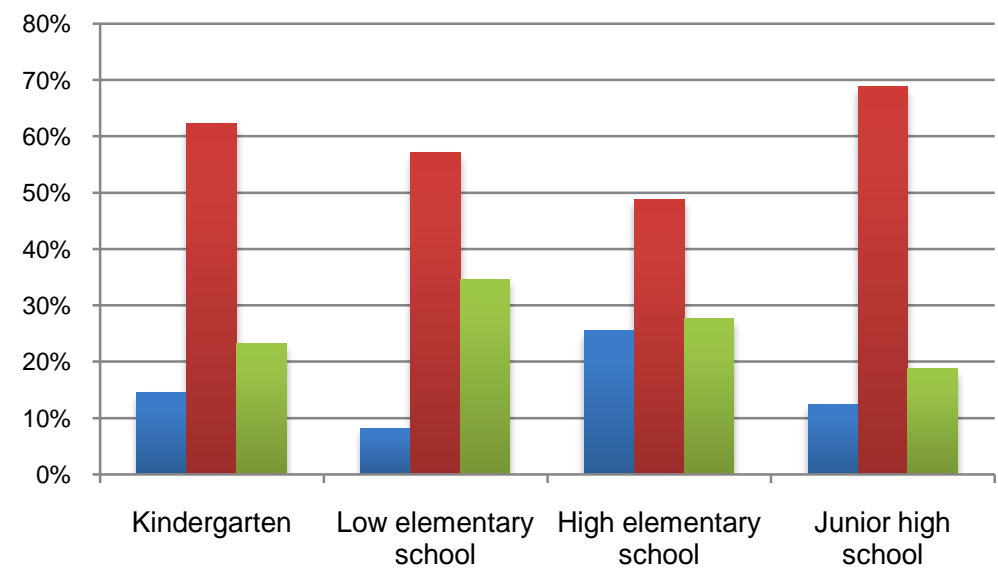

- High performance

- Medium performance

Low performance

Figure 5. Academic performance according to children scholar grade.

children with married, single, separated and divorced parents.

About parental school grade, parents (64\%) and mothers (60\%) with professional studies and postgraduate have children with higher academic performance (Figure 6).

Finally, in relation to the final diagnosis, there is a tendency in which children with cognitive problems have poor academic performance (50\%), followed by children with emotional problems (22\%), then children with physical sensory problems (12.0\%) and finally children with ADD/ADHD and learning disabilities $(8.0 \%)$.

\section{Discussion}

The population studied consisted of more children from the range of 4 to 10 years old, right handed laterality, who attend to low elementary education in 


\section{ACADEMIC PERFORMANCE ACCORDING TO PARENTAL MARITAL STATUS}

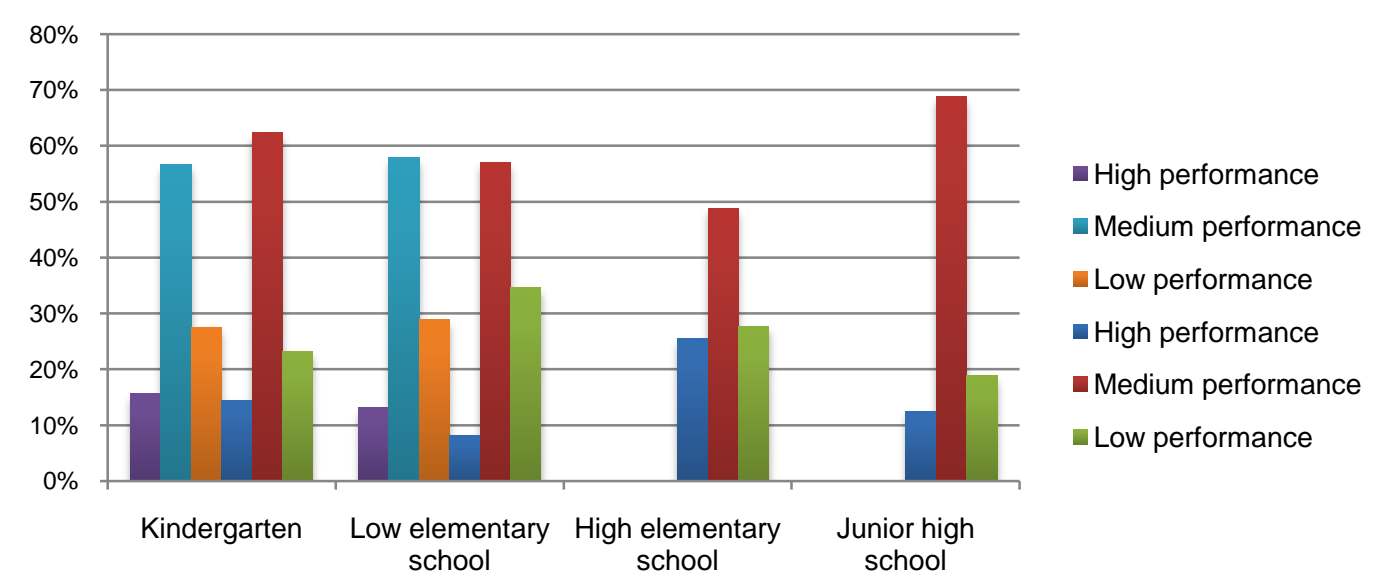

Figure 6. Academic performance according to parental marital status.

public schools, and monolingual type. Generally, it was found that academic performance levels in children from 6 - 13 years old of both genders were characterized by good performance, i.e. there is variability between capacity and expected performance according to their age and school grade.

From this, it was found that children from $11-16$ years old are the group with the highest percentage of good academic performance compared with children from 4 to 10 years old. As indicated in the literature reviewed, Ruíz de Miguel [4] mentions that in disadvantaged contexts, where the familiar cultural-educational level is limited, there is lower valuation and cultural pressure academic development, which conforms a less interest in educational issues by the parents. This means that economic possibilities determine the cultural and educational atmosphere in a family. In this sense, the families of privileged social classes have more training and choose to enroll their children to bilingual schools, being the reason why this type of school indicated a better academic performance.

A relation between parental age and academic performance levels of their children was found, so, parents of $51-67$ years old and mothers from 41 to 50 years old have children with good academic performance, indicating association between both conditions.

About the parental marital status, it was found that there are non-significant differences in academic performance of children with married parents, cohabiting, single, separated and divorced parents. For this reason, the null hypothesis was tested because there is no difference in academic performance of children with dysfunctional families and with functional families.

On the other hand, as the results indicate, there is a tendency for children with cognitive, emotional, physical and sensory problems to have low academic performance.

It is important to understand the relationship between parental education and children academic performance, as the results show that parents with profes- 
sional degree and postgraduate have children with good academic performance, compared with the parent with lower grade studies.

\section{Conclusion}

Finally, it is suggested further research to determine other factors that affect academic performance on children. Also, the findings provide information that could be considered in the development of psychoeducational intervention programs or treatment of children with learning problems and poor academic performance.

\section{References}

[1] Estrada, L. (2007) El Ciclo Vital de la Familia. De bolsillo, Mexico.

[2] Beltrán, J. and Bueno, J.A. (1995) Psicología de la educación. Boixareu Universitaria, Spain.

[3] Álvarez, N. (2007) Cuestiones de familia. Problemas y debates en torno a la familia contemporánea. Mar de Plata, Argentina.

[4] Ruiz de Miguel, C. (2001) Factores Familiares vinculados con el bajo rendimiento. Complutense de Educación Magazine, 12, 81-113.

[5] Ladrón de Guevara, C. (2000) Condiciones sociales y familiares y fracaso escolar. Doce Calles, Madrid.

[6] Condemarin, M. (1998) Madurez escolar. Andrés Bello, Chile.

[7] González-Pienda, J.A. (2003) El rendimiento escolar. Un análisis de las variables que lo condicionan. Galego-Portuguesa de Psicoloxía E Educación Magazine, 8, 247-258.

[8] American Psychiatric Association (2013) Guía de Consulta de los Criterios Diagnósticos del DSM-5. 5th Edition, Vol. 1, Madrid.

Submit or recommend next manuscript to SCIRP and we will provide best service for you:

Accepting pre-submission inquiries through Email, Facebook, LinkedIn, Twitter, etc.

A wide selection of journals (inclusive of 9 subjects, more than 200 journals)

Providing 24-hour high-quality service

User-friendly online submission system

Fair and swift peer-review system

Efficient typesetting and proofreading procedure

Display of the result of downloads and visits, as well as the number of cited articles

Maximum dissemination of your research work

Submit your manuscript at: http://papersubmission.scirp.org/

Or contact health@scirp.org 